\title{
Isolation, Characterization and Identification of Phosphate Solubilizing Bacteria from Maize Rhizosphere Soil
}

\author{
Ashwini R. Bhosale, V.G. Mulekar, K.L. Jaiswal* and A.S. Rothe \\ Department of Plant Pathology, College of Agriculture, Latur, India \\ *Corresponding author
}

\section{A B S T R A C T}

\begin{tabular}{|l|}
\hline Ke y w o r d s \\
Isolation, \\
Identification, \\
Pikovaskaya's agar \\
medium, PSB and \\
Bacillus subtilis
\end{tabular}

\section{Introduction}

Phosphorus (P) is a major growth limiting nutrient and unlike the case for nitrogen, there is no large atmospheric source that can be made biologically available for growth and development of plants. Biofertilizers are best defined as biologically active products or microbial inoculants containing one or more beneficial bacterial or fungal strains in easy to use and economical carrier materials which add, conserve and mobilize crop nutrients in the soil. Not all PGRs can be considered biofertilizers. There are bacteria that promote plant growth by control of deleterious organisms as bio-pesticides, but not biofertilizers. Similarly, bacteria can enhance plant growth by producing phytohormones and are regarded as bio enhancers, not biofertilizers (Mazid and Khan, 2014).

Several reports have examined the ability of different bacterial species to solubilize insoluble inorganic phosphate compounds, such as tricalcium phosphate, dicalcium phosphate, hydroxyl apatite, and rock phosphate. Among the bacterial genera with this capacity are Pseudomonas, Bacillus, Rhizobium, Burkholderia, Achromobacter, Agrobacterium, Microccocus, Aereobacter Flavobacterium and Erwinia. There are considerable populations of phosphate solubilizing bacteria in soil and in plant rhizospheres. These include both aerobic and 
anaerobic strains, with a prevalence of aerobic strains in submerged soils. A considerably higher concentration of phosphate solubilizing bacteria is commonly found in the rhizosphere in comparison with non-rhizosphere soil. The soil bacteria belonging to the genera Pseudomonas and Bacillus and fungi are more common. Depleting feedstock and increasing cost of fertilizers. This is becoming unaffordable by small and marginal farmers, depleting soil fertility due to widening gap between nutrient removal and supplies, growing concern about environmental hazards, increasing threat to sustainable agriculture. Besides above facts, the long-term use of biofertilizers is economical, ecofriendly, more efficient, productive and accessible to marginal and small farmers over chemical fertilizers. Keeping these issues in mind, present study was conducted.

\section{Materials and Methods}

\section{Collection of rhizosphere soil}

Rhizosphere soil samples of Maize were collected and samples were then air-dried, powdered and mixed well to represent a single sample from college farm, College of Agriculture, Latur.

\section{Preparation of medium}

The Pikovaskaya's agar medium (PVK) was found to be as selective media for the isolation of Phosphate solubilizing bacteria. The composition of the medium was as given in table 1 .

\section{Isolation of phosphate solubilizing bacteria}

Phosphate solubilizing bacteria were isolated from soil sample by serial dilution and spread plate method. One gram of soil sample was dispersed in $9 \mathrm{ml}$ of distilled water and was thoroughly shaken. One $\mathrm{ml}$ of the above solution was again transferred to $9 \mathrm{ml}$ of sterile distilled water to form $10^{-2}$ dilution. Similarly, upto $10^{-3}, 10^{-4}, 10^{-5}, 10^{-6}, 10^{-7}$ and $10^{-8}$. Each of $0.1 \mathrm{ml}$ dilution was spread on Pikovaskaya's agar medium (PVK) containing insoluble Tricalcium phosphate, incubated at $27-30^{\circ} \mathrm{C}$ for 7 days. Colonies showing halo zones were picked and purified by 5 times subculture method on Pikovaskaya's (PVK) agar medium for studying colony morphology. Sterility is the hallmark of any bacteriological isolation so the entire process was carried in the laminar airflow.

\section{Morphological and biochemical characterization of phosphate solubilizing bacteria}

Morphological characteristics of isolates viz. shape, size, margin, elevation, colour and texture was observed for their characterization and different biochemical tests including Gram's staining, catalase oxidation test, $\mathrm{KOH}$ (Potassium hydroxide test) and starch hydrolysis test.

\section{Gram's staining}

A loop full of the 24-36 hrs. old culture suspension of the test bacterium was smeared on clean glass slide, air dried and fixed by gentle heating on flame of the spirit lamp. Aqueous Crystal violet solution (0.5\%) was spread over fixed smear for 30 to 60 seconds and then washed with gentle flow of running tap water, for a minute. This stained smear was later flooded with Gram's iodine solution $(\%)$, for one minute and rinsed gently with tap water. Later decolorized with 95\% Ethanol solution, until color of crystal violet runoff, then washed with gentle flow of water. Finally stained with Safranin, as a counter stain for about 10 seconds, washed with gentle flow of water, air / blot dried and the slides observed under research microscope (40X). 


\section{Catalase oxidation test}

A loop full of 24-28 hrs old culture of the test bacterium was placed on the clean glass slide, to this a drop of $3 \%$ Hydrogen peroxide (H2O2) was mixed, allowed to react for few minutes and observed for production of gas bubbles.

\section{Potassium hydroxide (KOH) test}

A drop of $3 \%$ Potassium hydroxide was placed on clean glass slide, to this $48 \mathrm{hrs}$. old test bacterial culture was mixed with clean inoculation loop, stirred for 10 second and observed for appearance of slime threads.

\section{Starch hydrolysis test}

The autoclaved and cooled Starch agar medium (Appendix) was poured in sterile glass petri plates.

On solidification of the medium, pure culture of the test bacterium was streaked on it and incubated for $96 \mathrm{hrs}$ at $28 \pm 2^{0} \mathrm{C}$. Then these plates were flooded with Lugol's iodine and allowed to react for few minutes.

\section{Results and Discussion}

\section{Isolation and identification of phosphate solubilizing bacteria}

The isolates exhibiting halo zones was found (as shown in Plate.1) showing the capability of $\mathrm{p}$ solubilization was obtained from maize sample of $10^{-6}$ dilution. The colonies of developed PSB were convex, entire margin, white, smooth texture and measured about 0.5 $1.5 \times 1.5-6.0 \mu \mathrm{m}$. The bacterium was Gram positive, spore forming, motile rod shaped and growth was strictly aerobic (Table 2).

Different biochemical tests viz., Grams staining, catalase oxidation test, $\mathrm{KOH}$ (Potassium hydroxide test), starch hydrolysis etc. were attempted of phosphate solubilizing bacteria and the results obtained (Plate I) revealed that the phosphate solubilizing bacteria as Gram-positive, whereas, it showed positive reactions in respect of catalase oxidation test and starch hydrolysis and negative reactions to potassium hydroxide test. On the basis of biochemical reactions this isolate was identified as Bacillus subtilis.

Table.1 Composition of PVK medium

\begin{tabular}{|l|l|}
\hline Composition & Gm / Lit. \\
\hline Yeast Extract & $0.5 \mathrm{gm}$ \\
\hline Calcium phosphate & $5.0 \mathrm{gm}$ \\
\hline Ammonium sulphate & $0.5 \mathrm{gm}$ \\
\hline Potassium chloride & $0.2 \mathrm{gm}$ \\
\hline Magnesium sulphate & $0.1 \mathrm{gm}$ \\
\hline Manganese sulphate & $0.0001 \mathrm{gm}$ \\
\hline Ferrous sulphate & $0.0001 \mathrm{gm}$ \\
\hline Agar & $15.00 \mathrm{gm}$ \\
\hline Distilled water & $1000 \mathrm{ml}$ \\
\hline Ph & 7.00 \\
\hline
\end{tabular}


Table.2 Morphological characteristics of phosphate solubilizing bacteria

\begin{tabular}{|c|c|c|c|c|c|c|c|r|}
\hline Sr. No & Shape Size $(\boldsymbol{\mu m})$ & Gram Reaction & Margin & Elevation & Colour & Texture & Spore \\
1 & Rod & $0.5-1.5 \times 1.5-6.0$ & Positive & Entire & Convex & White & Smooth & + \\
\hline
\end{tabular}

Plate.1 Bacterial colony exhibiting halo zone of P solubilization

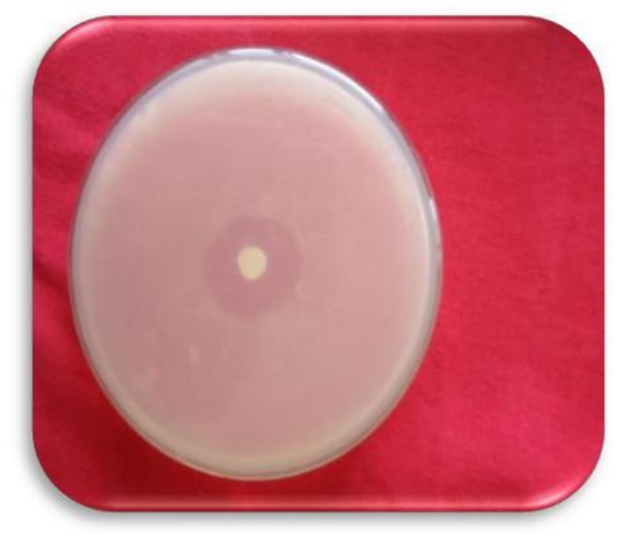

These results of present study obtained on morphological and biochemical characteristics of phosphate solubilizing bacteria are in conformity with earlier reports of several workers (Karpagam and Nagalakshmi, 2014; Susilowati et al., 2014; Baliah et al., 2016 and Baliah and Andal, 2017). They isolated phosphate solubilizing bacteria from rhizosphere soil on pikovaskayay's agar medium. They reported that, PSB isolates were selected from the colonies based on their ability to form a clear halo on pikovaskayay's agar medium.

\section{References}

Baliah, T. N. and Andal, P. S. (2017). In vitro characterization of phosphate solubilizing bacteria isolated from different agricultural fields. Int. $J$. Devel. 7 (16911- 16918).

Baliah, Tenzingh. N., Pandiarajan, G. and Makeshkumar, B. (2016). Isolation, identification and characterization of phosphate solubilizing bacteria from different crop soils of srivilliputtur taluka, Virudhu district, Tamilnadu. Tropical. Eco.57 (3): 465- 474.

Karpagam, T. and Nagalakshmi, P. K. (2014). Isolation and characterization of phosphate solubilizing microbes from agricultural soil. Int. J. Cur. Micro. App. Sci. 3 (3): 601-614.

Mazid, Mohd. and Khan, Taqi Ahmed. (2014). Future of bio-fertilizer in Indian agriculture: An overview. Int. J. Agri. Food. Res. 3 (3): 10-23.

Susilowati, L. E. and Syekhfani. (2014). Characterization of phosphate solubilizing bacteria isolated from $\mathrm{Pb}$ contaminated soils and their potential for dissolving tricalcium phosphate. $J$. Degraded. Mining. Lands Management. 1 (2): 57-62.

\section{How to cite this article:}

Ashwini R. Bhosale, V.G. Mulekar, K.L. Jaiswal and Rothe, A.S. 2019. Isolation, Characterization and Identification of Phosphate Solubilizing Bacteria from Maize Rhizosphere Soil. Int.J.Curr.Microbiol.App.Sci. 8(10): 1065-1068. doi: https://doi.org/10.20546/ijcmas.2019.810.125 